\title{
Occupational Exposure During Pregnancy and the Risk of Atopic Dermatitis in the Offspring
}

$$
\text { Case Report }
$$

Christensen $\mathrm{BH}^{1,2^{*}}$, Schlünssen $\mathrm{V}^{1}$, Thulstrup $\mathrm{AM}^{2}$, Hougaard $\mathrm{KS}^{3}$, Hansen $\mathrm{KS}^{4}$, Skadhauge $\mathrm{LR}^{5}$

${ }^{1}$ Department of Public Health, Section for Environment, Occupation and Health, Danish Ramazzini Centre, Aarhus University, Denmark.

${ }^{2}$ Department of Occupational Medicine, Danish Ramazzini Centre, Aarhus University Hospital, Denmark.

${ }^{3}$ The National Research Centre for the Working Environment, Copenhagen, Denmark.

${ }^{4}$ Department of Paediatrics, Herlev Hospital, University Hospital Copenhagen, Denmark.

${ }^{5}$ Department of Occupational Medicine, Hospital of South West Jutland, Denmark.

\begin{abstract}
Background: The prevalence of atopic dermatitis (AD) has increased considerably in the last decades. The major predisposing factor for $\mathrm{AD}$ is an inherited epithelial barrier defect due to loss-of-function in the filaggrin gene. Environmental factors are also hypothesised to cause $\mathrm{AD}$. The aim of the present study was to analyse whether maternal occupational exposure to allergens or irritants during pregnancy is associated with $\mathrm{AD}$ in the offspring.

Methods: A total of 41,724 mother-child pairs from The Danish National Birth Cohort were categorized according to maternal occupational exposure assessed by combining occupation during pregnancy and a job exposure matrix. $\mathrm{AD}$ in the offspring was defined by a combination of parentally reported AD and eczema in locations typical for AD.

Results: AD was identified in $14.9 \%$ and $11.7 \%$ of the children by age 18 months and 7 years, respectively. By age 18 months, maternal mixed low- and high molecular weight agents exposure (health care workers) during pregnancy was positively associated with AD (OR 1.07 (95\% CI: 0.98-1.16)). Maternal exposure to low molecular weight agents showed a borderline significantly decreased risk of $\mathrm{AD}$ (OR 0.88 (0.78-1.00)). By age 7, none of the maternal exposure groups were associated with a changed risk of $\mathrm{AD}$ in the offspring.

Conclusions: Our results do not suggest maternal exposure during pregnancy to be a significant risk factor for AD in the offspring. Exposure of pregnant women employed in the healthcare sector to e.g. antibiotics, latex and cleaning agents might pose a risk factor for $\mathrm{AD}$ in their offspring.
\end{abstract}

Keywords: Atopic Dermatitis; Prospective Cohort Study; Maternal Exposure; Prenatal Exposure; Occupational Exposure; Pregnancy; Epidemiology.

\section{*Corresponding Author:}

Berit Hvass Christensen $\mathrm{PhD}$,

Department of Public Health, Section for Environment, Occupation and Health, Danish Ramazzini Centre, Aarhus University, Bartholins Allé 2, 8000 Aarhus C, Denmark.

Tel: +4540322158

E-mail: berithvass@dadlnet.dk

Received: May 20, 2015

Accepted: June 25, 2015

Published: June 30, 2015

Citation: Christensen BH et al., (2015) Occupational Exposure During Pregnancy and the Risk of Atopic Dermatitis in the Offspring. Int J Clin Med Allergy. 03(2), 19-25. doi: http://dx.doi.org/10.19070/2332-2799150006

Copyright: Christensen $\mathbf{B H}^{\odot}$ 2015. This is an open-access article distributed under the terms of the Creative Commons Attribution License, which permits unrestricted use, distribution and reproduction in any medium, provided the original author and source are credited.

\section{Introduction}

Atopic dermatitis (AD) is a very frequent inflammatory skin disorder. The AD incidence is highest during the first two years of life and decreases later in childhood. The prevalence of $\mathrm{AD}$ has increased considerably in the last decades where it has doubled or tripled in the developed countries [1]. In urban Copenhagen, Denmark, the prevalence of AD increased from $17.3 \%$ in 1986 to $27.3 \%$ in 2001 in two random samples of children and adolescents [2]. The disease accumulates in families and a twin study showed that genes accounted for $82 \%$ of the individual susceptibility to develop AD [3]. The major predisposing factor for AD seems to be an inherited primary epithelial barrier defect due to loss-of-function in the filaggrin gene (FLG) [4]. A temporal pattern of FLG-associated atopic diseases has been characterized by an early onset of eczema and asthma, followed by subsequent development of sensitization in many patients [5]. Skin barrier dysfunction may therefore lead to sensitization due to increased skin permeability to environmental allergens. Since only one third of AD patients have been identified as carriers of the FLG mutation, other factors may partake in the development of AD [6].

We hypothesise, that maternal exposure to allergens and irritants during pregnancy influences foetal development of the immune system and predisposes the offspring to allergic disease. Research on maternal occupational exposure during pregnancy and the risk of $\mathrm{AD}$ in the offspring is sparse. The aim of the present study was to analyse whether maternal occupational exposure to allergens or irritants during pregnancy is associated with the development of $\mathrm{AD}$ in the offspring in order to elucidate potential 


\section{prevention possibilities.}

\section{Materials and Methods}

\section{Study population}

The study population originates from The Danish National Birth Cohort (DNBC), which includes 100,418 pregnancies from 1997 to 2002. Women were recruited at their first pregnancy consultation at their general practitioner. Participation implied two telephone interviews during pregnancy (week 12-16 and 30-35) and additional interviews 6 and 18 months after giving birth. By age 7 years, the mother answered an internet questionnaire on behalf of their children. Mothers without access to a PC were offered a hard copy version of the questionnaire. The present study use data from the first telephone interview comprising questions on maternal work, parental atopic diseases and prenatal risk factors for allergic disease in the child, and data on atopic dermatitis in the child collected at age 18 months and 7 years.

The first telephone interview was answered 92,892 times. A total of 2,396 women who were no longer pregnant at the time of the interview were excluded. Furthermore, 2,963 children from multiple births and 8,720 siblings were excluded since only singletons and the women's first pregnancy in the cohort sampling period were included. The questionnaire by age 7 was answered by 45,687 mother-child pairs of which 3,963 pairs were excluded due to missing information on maternal occupation. Thereby, a total of 41,724 mother-child pairs are eligible for the core analyses. Additional information on maternal exposure and potential risk factors during pregnancy was collected from the women 18 months after giving birth.

\section{Occupational Exposure}

Exposure during pregnancy was obtained by means of information on job-title (DISCO-codes, Danish International Standard Classification of Occupations, the Danish edition of ISCO-88) from the first telephone interview during pregnancy and a job exposure matrix (JEM) developed by Kennedy et al., [7], slightly modified by Christensen $\mathrm{BH}$ and Schlünssen V to match Danish working conditions.

The JEM included seven exposure groups, according to probable exposure: 1) High molecular weight agents (HMW); 2) low molecular weight agents and irritants (LMW); 3) high and/or low molecular weight agents (mixed); 4) farmers; 5) unclassifiable; 6) students; and 7) reference population. The HMW exposure group comprised exposure for grass pollen, animal dander, flour/grain etc. in bakers, gardeners/nursery workers, veterinarians and veterinarian's assistants. The LMW exposure group covered exposure to irritants, aerosols or dust from manufacturing of wood, textile, stone, rubber, plastics etc. in hairdressers, dentists, cooks, cleaners and processing of the mentioned materials. The mixed exposure group comprised exposure for antibiotics, latex and cleaning agents primarily in health care professionals. Farmers comprised exposure for grass pollen, animal dander and ammonia. The unclassifiable exposure group included subjects with jobs that involved different types of exposures, e.g. waiters, engineering technicians, biologists and shop managers. Being a student was assumed not to involve occupational exposure. The reference group comprised office workers, teachers and journalists.
Information regarding absence from work during pregnancy was obtained from the Danish DREAM database from the Danish Ministry of Employment in which all public transfer incomes are recorded week by week [8]. Women without absence from work were defined as those who did not receive compensation for more than 14 consecutive days at any time during the first 30 weeks of pregnancy.

\section{Definitions}

Information on $\mathrm{AD}$ in the offspring was obtained from the interview 18 months after giving birth and the 7-year follow-up questionnaire. $\mathrm{AD}$ was defined by parental report of $\mathrm{AD}$ at age 18 month AND an affirmative answer to the question on itchy rash in the locations known to be typical for $\mathrm{AD}$ (the elbows, the back of the knees and thighs, in front of the ankles, neck, and around eyes or ears) AND/OR report of persistent itchy rash in the locations known to be typical for AD at age 7 years. This definition complies with the protocol developed specifically for use in study of allergic diseases by The International Study of Asthma and Allergies in Childhood (ISAAC) [9]. Maternal atopy was defined by the mother herself reporting ever asthma, rhinitis or AD. Paternal atopy was defined by the mother's report of paternal asthma and/or rhinitis.

\section{Statistical analysis}

All analysis were performed in STATA SE12.0 (STATA corp., Texas, USA). Logistic regression analysis was used to examine the associations between maternal occupational exposure during pregnancy and AD in her child. The predictor variables included in the model were chosen a priori and comprised maternal atopy, smoking, use of antibiotics, folic acid, acetyl salicylic acid and paracetamol (acetaminophen) during pregnancy, having furry animals at home, the child being small for gestational age at birth (SGA) and sex. In a sub-analysis only women without absence from work during the first 30 weeks of pregnancy were included. Unless otherwise stated, the significance level was $\mathrm{p}<0.05$, twosided.

\section{Results}

AD was identified in 4,945 children $(14.9 \%)$ by age 18 months and 4,881 children (11.7\%) by age 7 years. By age 18 months, AD was most prevalent in children of mothers in the unclassifiable and the mixed exposure groups $(16.0 \%$ and $15.7 \%$, respectively), whereas farmers' children had the lowest prevalence (11.5\%). By age 7 years the differences in prevalence of $\mathrm{AD}$ in the offspring between the maternal exposure groups had almost vanished. AD at either 18 month or 7 years was identified in 7,566 children corresponding to a cumulative incidence proportion of $18.1 \%$. A total of 3,555 children $(71.9 \%)$ with AD by age 18 months had experienced remission of $\mathrm{AD}$ by age 7 years, while 2,462 children $(8.7 \%)$ without $\mathrm{AD}$ by age 18 months had developed AD during the follow-up. Children of farmers experienced the highest cumulative incidence proportion $(9.0 \%)$ in the follow-up period, in comparison with the other maternal exposure groups (data not shown).

Table 1 shows the characteristics of the study population by maternal exposure group. Mothers in the student group were younger and had a significantly higher prevalence of atopy than mothers 
in the other exposure groups. Parity differed only slightly between the groups, i.e. the proportion of mothers with parity 1-2 was significantly lower in students and the proportion of mothers with parity $3+$ was significantly higher in farmers compared with the other groups.

Intake of paracetamol during pregnancy was common in all exposure groups, but most prevalent in the mixed exposure group $(52.3 \%)$ and least prevalent among farmers $(39.6 \%)$. On average $17.5 \%$ reported use of antibiotics during pregnancy, with little fluctuation between groups. Use of folic acid during pregnancy was reported by more than half of the women in all exposure groups, but was significantly less among farmers. Significantly more women in the LMW group smoked compared with women in the other groups ( $33 \%$ and $28 \%$, respectively). Furry animals were common in the homes of all groups, especially among farmers $(68 \%)$. Farmers most often reported living in a rural environment with animals $(44 \%)$ compared with other groups $(15 \%$ or less).
A majority of mothers in the unclassifiable (56.4\%) and the reference group $(55.8 \%)$ had no absence from work, whereas only around a third (30-38\%) of the women in the other groups had no absence in the first 30 weeks (data not shown). Birth weight and sex were similar in the exposure groups, but a higher proportion of SGA was seen in children of mothers in the LMW group than in the other groups.

Figure 1 shows adjusted ORs of AD by age 18 months, age 7 years, and at 18 months and/or 7 years in the different maternal exposure groups. By age 18 months, maternal mixed exposure and unclassifiable exposure was positively associated with AD (OR 1.07 (95\% CI: 0.98-1.16) and OR 1.09 (95\% CI: 0.95-1.24), respectively), whereas maternal exposure for LMW agents was associated with a borderline significantly decreased risk of $\mathrm{AD}$ in the offspring (OR 0.88 (95\% CI: 0.78-1.00)). Overall, farming was associated with the numerically lowest risk of AD (OR 0.67 (95\% CI: $0.43-1.03))$. By age 7 , none of the maternal exposure groups were associated with $\mathrm{AD}$ in the offspring. For AD at 18 months and/or 7 years, maternal mixed exposure was associated with a

Table 1. Demographics, categorized according to maternal exposure during pregnancy into seven categories: High molecular weight (HMW), low molecular weight/irritants (LMW), mixed (a mixture of HMW and LMW), farmers, unclassifiable, students and references. The numbers are presented as $\%$ unless otherwise stated.

\begin{tabular}{|c|c|c|c|c|c|c|c|c|}
\hline & $\begin{array}{l}\text { HMW } \\
\mathrm{n}=409\end{array}$ & $\begin{array}{c}\mathrm{LMW} \\
\mathrm{n}=3,705\end{array}$ & $\begin{array}{c}\text { Mixed } \\
\mathrm{n}=7,722\end{array}$ & $\begin{array}{l}\text { Farmer } \\
\mathrm{n}=330\end{array}$ & $\begin{array}{c}\text { Unclassifiable } \\
n=2,405\end{array}$ & $\begin{array}{c}\text { Student } \\
\mathrm{n}=3,867\end{array}$ & $\begin{array}{l}\text { Reference } \\
\mathrm{n}=23,286\end{array}$ & $\begin{array}{c}\text { Missing, } \\
\%\end{array}$ \\
\hline \multicolumn{9}{|l|}{ Heredity: } \\
\hline Mothers atopy ${ }^{2}$ & 15.2 & 199 & 22.1 & 17.3 & 21.7 & 23.8 & 21.0 & 0 \\
\hline Fathers atopy ${ }^{b}$ & 22.2 & 23.0 & 26.9 & 23.6 & 28.8 & 29.3 & 26.9 & 1.0 \\
\hline \multicolumn{9}{|l|}{$\begin{array}{l}\text { Maternal parameters dur- } \\
\text { ing pregnancy: }\end{array}$} \\
\hline $\begin{array}{l}\text { Age, years, median } \\
(10 \% ; 90 \%)\end{array}$ & $29(24 ; 35)$ & $29(24 ; 35)$ & $30(25 ; 36)$ & $30(24 ; 36)$ & $31(26 ; 36)$ & $27(23 ; 33)$ & $30(26 ; 36)$ & 0 \\
\hline BMI, median $(10 \% ; 90 \%)$ & $23.0(19.5 ; 31.6)$ & $23.1(19.4 ; 30.5)$ & $22.6(19.4 ; 29.0)$ & $22.7(19.7 ; 28.4)$ & $22.3(19.4 ; 27.3)$ & $22.0(19.1 ; 27.5)$ & $22.4(19.4 ; 28.2)$ & 1.6 \\
\hline Parity: & & & & & & & & 0.1 \\
\hline 0 & 50.6 & 48.2 & 48.6 & 45.3 & 53.9 & 66.6 & 51.5 & \\
\hline 1 or 2 & 46.5 & 49.5 & 48.0 & 48.0 & 44.6 & 31.8 & 46.7 & \\
\hline $3+$ & 2.9 & 2.4 & 3.4 & 6.7 & 1.5 & 1.6 & 1.8 & \\
\hline \multicolumn{9}{|l|}{ Use of medicine: } \\
\hline ASA & 4.9 & 4.5 & 4.1 & 4.9 & 5.2 & 4.4 & 4.3 & 5.4 \\
\hline Paracetamol & 45.4 & 47.2 & 52.3 & 39.6 & 41.3 & 43.4 & 44.3 & 5.4 \\
\hline Antibiotics & 19.1 & 16.5 & 18.8 & 14.9 & 17.5 & 17.7 & 17.3 & 5.3 \\
\hline Folic acid & 55.5 & 56.0 & 56.1 & 52.1 & 55.4 & 58.3 & 58.3 & 5.2 \\
\hline Rural residence & 15.4 & 8.0 & 7.4 & 44.2 & 6.4 & 3.9 & 5.6 & 0 \\
\hline Furry animals $^{\mathrm{c}}$ & 63.6 & 49.1 & 41.4 & 67.6 & 34.6 & 29.6 & 35.5 & 0 \\
\hline Smoking: & & & & & & & & 0 \\
\hline no use of tobacco & 75.3 & 67.1 & 77.3 & 82.1 & 85.3 & 79.1 & 81.5 & 0 \\
\hline 1-10 cigarettes/day & 9.5 & 15.4 & 11.8 & 7.9 & 8.0 & 10.9 & 10.4 & 0 \\
\hline$>10$ cigarettes/day & 15.2 & 17.4 & 10.9 & 10.0 & 6.7 & 10.0 & 8.2 & 0 \\
\hline \multicolumn{9}{|l|}{ Demographics at birth: } \\
\hline Gender: Boy & 50.1 & 51.1 & 51.5 & 50.3 & 51.7 & 51.8 & 51.2 & 0 \\
\hline Birth weight, $\mathrm{kg}$, median & $3.60(2.90 ; 4.30)$ & $3.58(2.88 ; 4.25)$ & $3.60(2.95 ; 4.25)$ & $3.65(2.95 ; 4.29)$ & $3.60(2.98 ; 4.26)$ & $3.58(2.95 ; 4.21)$ & $3.60(2.95 ; 4.25)$ & \\
\hline \multicolumn{9}{|l|}{$(10 \% ; 90 \%)$} \\
\hline Small for gestational age & 9.6 & 10.8 & 8.7 & 7.9 & 8.5 & 9.7 & 8.7 & 0.3 \\
\hline \multicolumn{9}{|l|}{ 7-year follow-up: } \\
\hline \multicolumn{9}{|l|}{ Mother: } \\
\hline Smoking & 19.3 & 27.5 & 17.5 & 13.9 & 10.7 & 16.1 & 15.1 & 0 \\
\hline \multicolumn{9}{|l|}{ Father: } \\
\hline Smoking & 27.9 & 31.1 & 22.8 & 18.5 & 18.2 & 21.5 & 20.4 & 0 \\
\hline \multicolumn{9}{|l|}{ Child: } \\
\hline ETS exposure $^{d}$ & 37.4 & 43.6 & 31.6 & 26.4 & 23.8 & 30.0 & 28.1 & 0 \\
\hline
\end{tabular}

a: Atopy defined as asthma, rhinitis and/or atopic dermatitis, b: Atopy defined as paternal asthma and/or rhinitis reported by mother, c: Furry animals defined as dogs, cats and horses,

d: Environmental Tobacco Smoke exposure 
Figure 1. Adjusted logistic regression analysis on the association between maternal exposure during pregnancy and atopic dermatitis by age 18 months, 7 years, and 18 months and/or 7 years.

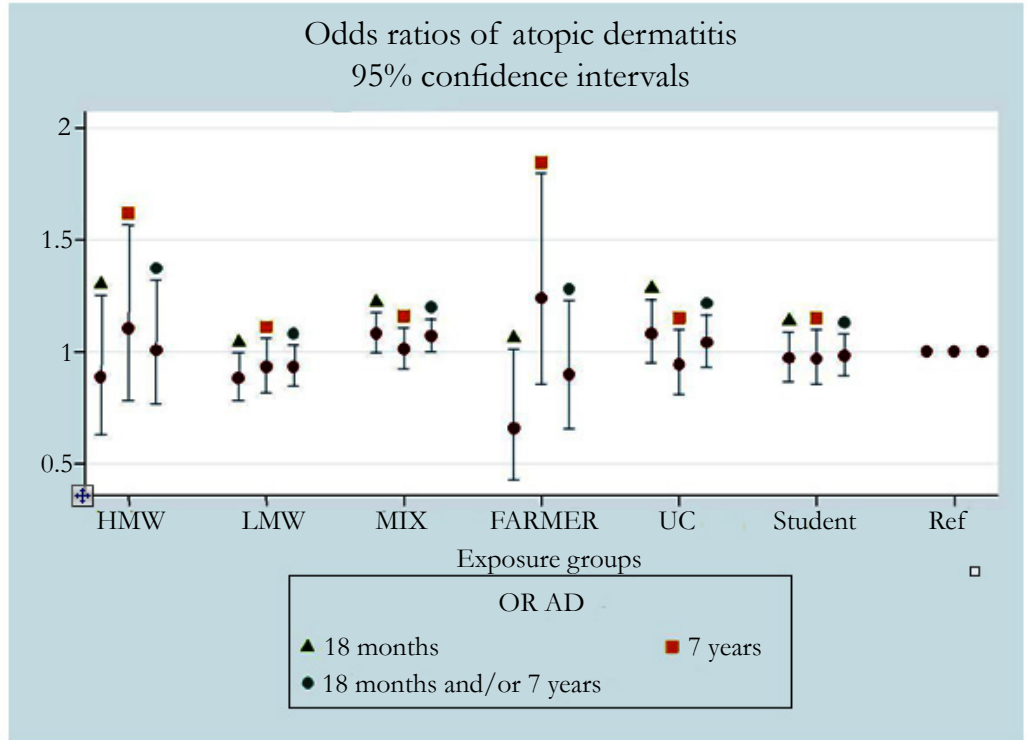

borderline significantly increased risk of AD (OR 1.07 (95\% CI: 1.00-1.15))

Table 2 shows the outcome of the crude and adjusted logistic regression models and predictor variables included in the two models. In comparison with the figures in model 1 , not being absent from work during the first 30 weeks of gestation (model 2) seems to increase the effect of maternal work exposure on the risk of $\mathrm{AD}$. In the latter model, the risk of $\mathrm{AD}$ in children of mothers in the mixed exposure group showed a borderline significantly increased OR 1.14 (95\% CI: 1.00-1.29) by age 18 months. By age 7 years, children of LMW exposed women showed a significantly decreased risk of AD (OR 0.80 (95\% CI: 0.64-0.99)).

In both age groups, maternal age of 30-34, atopy and intake of paracetamol and antibiotics during pregnancy were associated with an increased risk of AD in the offspring, whereas having furry animals at home was associated with a significantly decreased risk of $\mathrm{AD}$. By age 18 months, being male was associated with an increased risk of $\mathrm{AD}$, whereas maternal $\mathrm{BMI}$ above 30 was associated with a decreased risk of $\mathrm{AD}$. By age 7 years, maternal $\mathrm{BMI}<20$ and maternal age +35 was associated with an increased risk of $\mathrm{AD}$, whereas male sex was associated with a reduced risk of $\mathrm{AD}$ in the child.

\section{Discussion}

In this well powered birth cohort study there was overall no association between maternal occupational exposure and $\mathrm{AD}$ in the offspring. Maternal occupational exposure to allergens or irritants during pregnancy was positively associated with $\mathrm{AD}$ by age 18 months in children of women with mixed exposure (mainly health care workers). Maternal employment in jobs with probable exposure to LMW agents was associated with a borderline significantly decreased risk of AD in the offspring. By age 18 months farmers' children had the lowest prevalence of AD. At the age of 7 years, there was no difference in prevalence. A large percentage $(71.9 \%)$ of the children with $\mathrm{AD}$ at 18 months were no longer AD sufferers at age 7 years. Maternal atopy and intake of paracetamol and antibiotics during pregnancy were associated with increased risk of having $\mathrm{AD}$, whereas furry animals in the home reduced the risk. Being male increased the risk of AD significantly by age 18 months but conferred significant protection against AD by age 7 years.

Despite a major genetic influence on the development of $\mathrm{AD}$, environmental factors may have an impact on the increasing prevalence of AD during the last decades. Research on maternal occupational exposure during pregnancy and the risk of $\mathrm{AD}$ in the offspring is sparse. In a Danish follow-up study of 7,844 children, analysis of questionnaire based maternal job titles in third trimester of pregnancy showed significantly elevated adjusted ORs of reported doctor diagnosed either eczema in the 14-18 year old children for occupational groups such as "social workers", "teachers" and "sewers and embroiderers" [10]. These results suggest that certain maternal occupations during pregnancy are associated with atopic diseases in the offspring. In the present study, sewers and embroiderers were included in the LMW exposure group in which we showed a decreased risk of $\mathrm{AD}$, whereas social workers and teachers were included in the reference group.

In a cohort of 411 children born of mothers with asthma, being unemployed versus being non-professional was associated with a significantly increased risk of AD in the offspring by age 3 years, whereas no increased risk was seen for neither being student nor being professional versus being non-professional based on DISCO classification and ISCO-88 [11]. In the same study remarkably few prenatal, perinatal, and postnatal exposures including those related to the hygiene hypothesis exerted significant influence on disease expression.

In the last decades a number of studies have shown a lower frequency of asthma, hay fever and atopic sensitization in children growing up on a farm. These results suggest a protective effect of exposure to farm environment in utero on the risk of atopic diseases in the offspring [12-14]. A cross-sectional study of 1,333 children of female farmers showed that maternal exposure to animals at least once a day during pregnancy reduced the risk of $\mathrm{AD}$ in the children by $42 \%$ after adjustment for potential confounders, and a protective dose-response association was demonstrated for exposure to grain or hay products and the risk of hay fever and AD [15]. 
Table 2. Unadjusted and adjusted logistic regression models showing the association between mothers' occupational exposure and other potential risk factors during pregnancy and AD in the child by age 18 months, 7 year and 18 months and/or 7 years.

\begin{tabular}{|c|c|c|c|c|c|c|c|c|c|c|c|c|}
\hline \multirow[t]{2}{*}{ Model 1} & \multicolumn{2}{|c|}{$\begin{array}{l}\mathrm{AD} \text { at } 18 \text { months } \\
\text { Crude }(\mathrm{n}=33,206)\end{array}$} & \multicolumn{2}{|c|}{$\begin{array}{c}\text { Adjusted } \\
(\mathrm{n}=30,881)\end{array}$} & \multicolumn{2}{|c|}{$\begin{array}{c}\mathrm{AD} \text { at } 7 \text { years } \\
\text { Crude }(\mathrm{n}=41,724)\end{array}$} & \multicolumn{2}{|c|}{$\begin{array}{l}\text { Adjusted } \\
(\mathrm{n}=38,656)\end{array}$} & \multicolumn{2}{|c|}{$\begin{array}{c}\mathrm{AD} \text { at } 18 \text { months and/ } \\
\text { or } 7 \text { years } \\
\text { Crude }(\mathrm{n}=41,724)\end{array}$} & \multicolumn{2}{|c|}{$\begin{array}{c}\text { Adjusted } \\
(\mathrm{n}=38,656)\end{array}$} \\
\hline & OR & $(95 \% \mathrm{CI})$ & OR & $(95 \% \mathrm{CI})$ & OR & $(95 \% \mathrm{CI})$ & OR & $(95 \% \mathrm{CI})$ & OR & $(95 \% \mathrm{CI})$ & OR & $(95 \% \mathrm{CI})$ \\
\hline $\begin{array}{c}\text { High mo- } \\
\text { lecular }\end{array}$ & 0.75 & $(0.53 ; 1.05)$ & 0.87 & $(0.61 ; 1.23)$ & 0.9 & $(0.66 ; 1.23)$ & 0.97 & $(0.70 ; 1.35)$ & 0.9 & $(0.69 ; 1.17)$ & 1.01 & $(0.77 ; 1.33)$ \\
\hline Low & 0.83 & $(0.74 ; 0.93)$ & 0.88 & $(0.78 ; 1.00)$ & 0.9 & $(0.81 ; 1.01)$ & 0.91 & $(0.81 ; 1.03)$ & 0.9 & $(0.82 ; 0.98)$ & 0.93 & $(0.85 ; 1.03)$ \\
\hline \multicolumn{13}{|l|}{$\begin{array}{c}\text { Molecular/ } \\
\text { irritants }\end{array}$} \\
\hline Mixed & 1.06 & \begin{tabular}{|l|}
$(0.98 ; 1.15)$ \\
\end{tabular} & 1.07 & $(0.98 ; 1.16)$ & 0.99 & $(0.92 ; 1.08)$ & 0.99 & $(0.92 ; 1.08)$ & 1.06 & $(0.99 ; 1.13)$ & 1.07 & $(1.00 ; 1.15)$ \\
\hline Farmer & 0.74 & $(0.51 ; 1.09)$ & 0.67 & $(0.43 ; 1.03)$ & 1.09 & $(0.78 ; 1.51)$ & 1.15 & $(0.82 ; 1.63)$ & 0.94 & $(0.71 ; 1.26)$ & 0.9 & $(0.66 ; 1.24)$ \\
\hline $\begin{array}{c}\text { Unclassifi- } \\
\text { able }\end{array}$ & 1.08 & $(0.95 ; 1.23)$ & 1.09 & $(0.95 ; 1.24)$ & 0.93 & $(0.82 ; 1.07)$ & 0.93 & $(0.81 ; 1.07)$ & 1.04 & $(0.93 ; 1.15)$ & 1.04 & $(0.93 ; 1.16)$ \\
\hline Student & 1.02 & $(0.92 ; 1.14)$ & 0.98 & $(0.87 ; 1.10)$ & 1.01 & $(0.91 ; 1.13)$ & 1 & $(0.89 ; 1.12)$ & 1 & $(0.92 ; 1.09)$ & 0.98 & $(0.89 ; 1.08)$ \\
\hline Reference & 1 & & 1 & & 1 & & 1 & & 1 & & 1 & \\
\hline \multicolumn{13}{|l|}{ Age: } \\
\hline $16-24$ & & & 1.04 & $(0.92 ; 1.18)$ & & & 1.11 & $(0.99 ; 1.26)$ & & & 1.06 & $(0.96 ; 1.18)$ \\
\hline $25-29$ & & & 1 & & & & 1 & & & & 1 & \\
\hline $30-34$ & & & 1.09 & $(1.01 ; 1.17)$ & & & 1.09 & $(1.01 ; 1.18)$ & & & 1.1 & $(1.04 ; 1.17)$ \\
\hline 35 & & & 1.02 & $(0.92 ; 1.13)$ & & & 1.1 & $(1.00 ; 1.22)$ & & & 1.07 & $(0.98 ; 1.16)$ \\
\hline \multicolumn{13}{|l|}{ BMI: } \\
\hline$<20$ & & & 1 & $(0.91 ; 1.09)$ & & & 1.09 & $(1.00 ; 1.19)$ & & & 1.05 & $(0.98 ; 1.13)$ \\
\hline $20-24$ & & & 1 & & & & 1 & & & & 1 & \\
\hline $25-29$ & & & 0.92 & $(0.84 ; 1.00)$ & & & 0.97 & $(0.89 ; 1.06)$ & & & 0.96 & $(0.89 ; 1.03)$ \\
\hline+30 & & & 0.79 & $(0.69 ; 0.91)$ & & & 0.93 & $(0.82 ; 1.06)$ & & & 0.88 & $\begin{array}{l}(0.79 ; \\
0.98) \\
\end{array}$ \\
\hline $\begin{array}{c}\text { Maternal } \\
\text { atopy }\end{array}$ & & & 1.51 & $(1.41 ; 1.62)$ & & & 1.43 & $(1.33 ; 1.54)$ & & & 1.49 & $(1.40 ; 1.58)$ \\
\hline \multicolumn{13}{|l|}{ Smoking: } \\
\hline No use & & & 1 & & & & 1 & & & & 1 & \\
\hline $\begin{array}{l}1-10 \text { ciga- } \\
\text { rettes } / \text { day }\end{array}$ & & & 0.94 & $(0.85 ; 1.05)$ & & & 1.14 & $(1.04 ; 1.26)$ & & & 0.98 & $(0.90 ; 1.07)$ \\
\hline $\begin{array}{l}>10 \text { ciga- } \\
\text { rettes/day }\end{array}$ & & & 1.02 & $(0.91 ; 1.14)$ & & & 1.05 & $(0.94 ; 1.17)$ & & & 1.01 & $(0.92 ; 1.11)$ \\
\hline Folic acid & & & 1.04 & $(0.97 ; 1.11)$ & & & 0.95 & $(0.89 ; 1.01)$ & & & 1.01 & $(0.96 ; 1.07)$ \\
\hline $\begin{array}{c}\text { Paraceta- } \\
\text { mol }\end{array}$ & & & 1.06 & $(1.00 ; 1.13)$ & & & 1.11 & $(1.04 ; 1.18)$ & & & 1.08 & $(1.03 ; 1.14)$ \\
\hline ASA & & & 0.93 & $(0.79 ; 1.09)$ & & & 1.09 & $(0.94 ; 1.27)$ & & & 0.99 & $(0.87 ; 1.13)$ \\
\hline Antibiotics & & & 1.08 & $(1.00 ; 1.18)$ & & & 1.08 & $(1.00 ; 1.17)$ & & & 1.07 & $(1.00 ; 1.14)$ \\
\hline $\begin{array}{c}\text { Furry } \\
\text { animals }\end{array}$ & & & 0.85 & $(0.80 ; 0.91)$ & & & 0.86 & $(0.80 ; 0.91)$ & & & 0.85 & $\begin{array}{c}(0.80 ; \\
0.90) \\
\end{array}$ \\
\hline SGA & & & 0.95 & $(0.85 ; 1.06)$ & & & 0.89 & $(0.79 ; 1.00)$ & & & 0.93 & $(0.85 ; 1.02)$ \\
\hline Boy & & & 1.26 & $(1.18 ; 1.34)$ & & & 0.73 & $(0.69 ; 0.78)$ & & & 0.98 & $\begin{array}{l}(0.93 ; \\
1.04) \\
\end{array}$ \\
\hline \multicolumn{13}{|l|}{ Parity: } \\
\hline 0 & & & 1 & & & & 1 & & & & 1 & \\
\hline 1 or 2 & & & 0.96 & $(0.89 ; 1.03)$ & & & 0.98 & $(0.92 ; 1.06)$ & & & 0.98 & $(0.92 ; 1.03)$ \\
\hline $3+$ & & & 1.07 & $(0.85 ; 1.34)$ & & & 0.93 & $(0.74 ; 1.17)$ & & & 0.97 & $(0.80 ; 1.17)$ \\
\hline Model 2 & $\begin{array}{c}(\mathrm{n}=15, \\
133)\end{array}$ & & $(\mathrm{n}=14,063)$ & & $(\mathrm{n}=18,848)$ & & $(\mathrm{n}=17,490)$ & & $(\mathrm{n}=18,484)$ & & $(\mathrm{n}=17,490)$ & \\
\hline $\begin{array}{c}\text { High mo- } \\
\text { lecular }\end{array}$ & 0.62 & $(0.32 ; 1.20)$ & 0.71 & $(0.35 ; 1.42)$ & 0.86 & $(0.48 ; 1.53)$ & 1.02 & $(0.56 ; 1.87)$ & 0.75 & $(0.45 ; 1.23)$ & 0.84 & $(0.49 ; 1.43)$ \\
\hline Low & 0.85 & $(0.70 ; 1.04)$ & 0.91 & $(0.73 ; 1.13)$ & 0.73 & $(0.59 ; 0.90)$ & 0.8 & $(0.64 ; 0.99)$ & 0.81 & $(0.68 ; 0.95)$ & 0.86 & $(0.72 ; 1.03)$ \\
\hline \multicolumn{13}{|l|}{$\begin{array}{c}\text { molecular/ } \\
\text { irritants }\end{array}$} \\
\hline Mixed & 1.12 & $(0.99 ; 1.26)$ & 1.14 & $(1.00 ; 1.29)$ & 0.94 & $(0.83 ; 1.07)$ & 0.95 & $(0.83 ; 1.09)$ & 1.07 & $(0.96 ; 1.18)$ & 1.08 & $(0.97 ; 1.21)$ \\
\hline Farmer & 0.58 & $(0.30 ; 1.12)$ & 0.55 & $(0.27 ; 1.14)$ & 1.08 & $(0.64 ; 1.82)$ & 1.1 & $(0.61 ; 1.97)$ & 0.84 & $(0.52 ; 1.35)$ & 0.81 & $(0.47 ; 1.38)$ \\
\hline $\begin{array}{c}\text { Unclassifi- } \\
\text { able }\end{array}$ & 1.16 & $(0.98 ; 1.37)$ & 1.17 & $(0.98 ; 1.39)$ & 0.85 & $(0.71 ; 1.02)$ & 0.84 & $(0.70 ; 1.02)$ & 1.04 & $(0.90 ; 1.20)$ & 1.05 & $(0.91 ; 1.22)$ \\
\hline Reference & 1 & & 1 & & 1 & & 1 & & 1 & & 1 & \\
\hline
\end{tabular}

Model 1: maternal age, pre-pregnancy BMI, atopy, smoking during pregnancy, use of medication during pregnancy, furry animal ownership during pregnancy, parity, SGA and sex of the child. Model 2: As model 1, but including only the subgroup of women with no absence from work during the first 30 weeks of pregnancy according to DREAM data. 
A recent review on $\mathrm{AD}$ and the hygiene hypothesis showed convincing evidence for an inverse relationship between helminth infections and AD, and evidence to support a protective effect of endotoxins, early day care, farm animal and dog exposure in early life, which is likely to be due to a general increase in exposure to non-pathogenic microbes [16]. The results of the present study showed only a tendency to a protective effect of farming during pregnancy on the risk of $\mathrm{AD}$ in children by age 18 months, but having furry animals was associated with a significantly decreased OR of $\mathrm{AD}$ by both age levels. Based on our findings and the results of other studies early change of the microbiome is likely to influence the risk of atopy, and the protective role of the microbiome would explain that use of antibiotics during pregnancy and in early life may increase AD in the offspring by eliminating microbes with a protective effect on the immune system [17]. However, a follow-up study of 31,471 mother-child pairs enrolled in the Danish National Birth Cohort showed that maternal microbial exposure before or during pregnancy as reflected by maternal employment in child-care institution did not protect the offspring against $\mathrm{AD}[18]$.

\section{Confounding}

The few observed associations between maternal exposure during pregnancy and AD in the offspring may be due to chance or confounding. Postnatal factors such as breastfeeding and early day care have to be considered [19,20], but in the present study only $0.2 \%$ of the mothers had never breastfeed, and more than $90 \%$ of the children attended day care from very early age. Thus, it is very unlikely that these factors influenced our results considerably. The use of paracetamol has consistently been associated with an increased risk of atopic disease which is supported by the findings in our study.

\section{Limitations}

The DNBC is one of the largest birth cohorts in the World so far. However, inclusion into the cohort was done by the general practitioner or midwife. Only about $26 \%$ of all the pregnant women living in Denmark in the inclusion period actually participated [21]. Furthermore, the number of mother-child pairs eligible for analyses in the present study represented only $41.6 \%$ of the original study population. In comparison with non-participants, participants were older, slimmer, smoked less, were better educated and belonged in higher socioeconomic groups, lived in urban areas and was less likely to have furry animals [22]. In addition, women with allergic diseases may avoid certain types of occupations, and employees with work related asthma or allergy may be advised to avoid or reduce occupational exposure to allergens leaving non-atopic women to work in occupations where there is a high risk of developing allergic diseases (healthy worker effect). However, the proportion of women with atopy did not differ between the exposure groups, except in the group of students, in which there was a higher proportion of atopic women than in the other groups. Furthermore, participation in the present study was independent of reported atopic disease. If present, a tendency to avoid high risk exposure among allergic mothers probably underestimates any true associations but may overestimate associations to low risk exposure.

The occupational exposure measures were rather crude, as expo- sure assessment was based on information on job titles and the overall probability of exposures for each job type. This implies a risk of non-differential exposure misclassification due to differences in work tasks within the groups.

In this large-scale epidemiological study no objective diagnosis of $\mathrm{AD}$ was available. We defined atopic dermatitis by a combination of parentally reported atopic dermatitis and eczema in locations typical for atopic dermatitis. These questions have been validated against a clinical investigation for atopic dermatitis and were deemed suitable for defining atopic dermatitis in large scale epidemiological studies [23]. However, since the diagnosis of AD in the present study is based on parental observation, misclassification of disease cannot be excluded. We have no reason to believe that the misclassification should be differential. Parental report of physician's diagnoses may be more accurate but different access to medical care and/or ability to understand the medical information given may lead to potential differential misclassification of diagnoses.

Because DNBC is a prospective study and the women answered questions about their immediate situation at all times and the current held job is stated in the interview during pregnancy, we believe there is no risk of recall bias in the study.

\section{Interpretation}

Loss-of-function in the filaggrin gene is the major predisposing factor for $\mathrm{AD}$ [4], and it has been discovered that filaggrin mutations dispose to early onset of $\mathrm{AD}$ and severe disease that continue in adulthood [11]. However, in the present study early exposure to allergens or irritants also seems to influence the expression of early symptoms and the time course of $\mathrm{AD}$, whereas the overall risk of persistent disease is unchanged. Chemical agents have been proposed to influence development of atopic disease in the offspring by a number of mechanisms [24]. Antigens may be transferred across the placenta or via the amniotic fluid to the gut-associated lymphoid tissue in the foetus allowing sensitisation to take place [25]. Maternal allergic response to antigen exposure during pregnancy increases the production of Th2 weighted cytokines and chemokines in the mother, which may affect the foetal development $[25,26]$. Thus, maternal exposure during pregnancy can promote an excessive or prolonged Th2skewed immunity after birth and exaggerate the normal dominance of Th2 during and after pregnancy and thereby increase the propensity of developing allergy [27-29]. Finally small placental bleedings during late pregnancy or at delivery may transfer $\mathrm{IgE}$ directly from the mother to the foetus leading to antigen presentation very early in life [30]. HMW agents and some LMW agents act through IgE-mediated immunological mechanisms, whereas most LMW chemicals act through immunological mechanisms that are not related to $\mathrm{IgE}$ antibodies or by non-immunological mechanisms.

We observed a positive association between exposure to mixed agents comprising antibiotics, latex and cleaning agents during pregnancy and risk of AD in children by age 18 months. Antibiotics and latex are known IgE mediated sensitizers, and alcoholic and chlorine-releasing cleaners may elicit irritation and may contain sensitizers such as disinfectants, amines, pinene, or limonene. Specific sensitization of the foetus due to maternal exposure is 
therefore plausible.

\section{Conclusion}

No overall association was seen between maternal occupational exposure to allergens and AD in the offspring at age 18 month and 7 year. However, early exposure seems to influence the temporal aspect of $\mathrm{AD}$. The observed positively associated risk of AD by age 18 months in the children of women with mixed exposure may reflect maternal exposure to e.g. antibiotics, latex and cleaning agents during pregnancy as a risk factor for $\mathrm{AD}$ in the offspring. The underlying reason for observation of decreased risk of $\mathrm{AD}$ in the children of women with exposure to LMW agents during pregnancy remains unclear. The main aim of the study was to explore the impact of exposure on the foetus, and due to the epidemiological approach, we are not able to identify whether an effect is sensitization directly on the foetus or via a maternal or foetal alteration of cytokines and chemokines. As IgE mediated sensitization probably plays a minor role in the aetiology of $\mathrm{AD}$, an alteration of cytokines and chemokines seems the most plausible explanation. This will be of interest to study in the future.

\section{Acknowledgements/Funding}

The study is part of the Danish collaborative MINERVA project (www.minervanet.dk) addressing occupational risks to human reproduction, supported by a grant from the Danish Working Environment Research Fund (contract 20080016458). Additional funding was obtained from Aarhus University and by the Danish Graduate School of Public Health Science (GRASPH).

\section{References}

[1]. Ricci G, Patrizi A, Giannetti A, Patrizi A, Dondi A, et al. (2010) Does improvement management of atopic dermatitis influence the appearance of respiratory allergic diseases? A follow-up study. Clin Mol Allergy 8: 8.

[2]. Stensen L, Thomsen SF, Backer V (2008) Change in prevalence of atopic dermatitis between 1986 and 2001 among children. Allergy Asthma Proc 29(4): 392-396.

[3]. Thomsen SF, Ulrik CS, Kyvik KO, Hjelmborg JVB, Skadhauge L, et al. (2007) Importance of genetic factors in the etiology of atopic dermatitis: a twin study. Allergy Asthma Proc 28(5): 535-539.

[4]. Palmer CN, Irvine AD, Terron-Kwiatkowski A, Zhao Y, Liao H, et al. (2006) Common loss-of-function variants of the epidermal barrier protein filaggrin are a major predisposing factor for atopic dermatitis. Nat Genet 38(4): 441446.

[5]. Bonnelykke K, Pipper CB, Tavendale R, Palmer CN, Bisgaard H (2010) Filaggrin gene variants and atopic diseases in early childhood assessed longitudinally from birth. Pediatr Allergy Immunol 21(6): 954-961.

[6]. Novak N, Leung DY (2011) Advances in atopic dermatitis. Curr Opin Immunol 23(6): 778-783.

[7]. Kennedy SM, Le MN, Choudat D, Kauffmann F (2000) Development of an asthma specific job exposure matrix and its application in the epidemiological study of genetics and environment in asthma (EGEA). Occup Environ Med 57(9): 635-641.

[8]. Lund T, Kivimaki M, Christensen KB, Labriola M (2009) Socio-economic differences in the association between sickness absence and mortality: the prospective DREAM study of Danish private sector employees. Occup Environ Med 66(3): 150-153.
[9]. Beasley R, Asthma TIS (1998) Worldwide variation in prevalence of symptoms of asthma, allergic rhinoconjunctivitis, and atopic eczema: ISAAC. The International Study of Asthma and Allergies in Childhood (ISAAC) Steering Committee. Lancet 351(9111): 1225-1232.

[10]. Magnusson LL, Wennborg H, Bonde JP, Olsen J (2006) Wheezing, asthma, hay fever, and atopic eczema in relation to maternal occupations in pregnancy. Occup Environ Med 63(9): 640-646.

[11]. Bisgaard H, Halkjaer LB, Hinge R, Giwercman C, Palmer C et al. (2009) Risk analysis of early childhood eczema. J Allergy Clin Immunol 123(6): 1355-1360.

[12]. Riedler J, Braun-Fahrlander C, Eder W, Schreuer M, Waser M, et al. ( 2001) Exposure to farming in early life and development of asthma and allergy: a cross-sectional survey. Lancet 358(9288): 1129-1133.

[13]. Ege MJ, Bieli C, Frei R, van Strien RT, Riedler J (2006) Prenatal farm exposure is related to the expression of receptors of the innate immunity and to atopic sensitization in school-age children. J Allergy Clin Immunol 117(4): 817-823.

[14]. Ege MJ, Herzum I, Buchele G, Krauss-Etschmann S, Lauener RP (2008) Prenatal exposure to a farm environment modifies atopic sensitization at birth. J Allergy Clin Immunol 122(2): 407-412.

[15]. Douwes J, Cheng S, Travier N, Cohet C, Niesink A, et al. (2008) Farm exposure in utero may protect against asthma, hay fever and eczema. Eur Respir J 32(3): 603-611.

[16]. Flohr C, Yeo L (2011) Atopic dermatitis and the hygiene hypothesis revisited. Curr Probl Dermatol 41: 1-34.

[17]. McKeever TM, Lewis SA, Smith C, Hubbard R (2002) The importance of prenatal exposures on the development of allergic disease: a birth cohort study using the West Midlands General Practice Database. Am J Respir Crit Care Med 166(6): 827-832.

[18]. Hersoug LG, Benn CS, Simonsen JB, Kamper-Jørgensen M, Linneberg A (2008) Maternal employment in child-care institutions and the risk of infant wheeze and atopic dermatitis in the offspring. Pediatr Allergy Immunol 19(8): 688-695.

[19]. Benn CS, Melbye M, Wohlfahrt J, Björkstén B, Aaby P (2004) Cohort study of sibling effect, infectious diseases, and risk of atopic dermatitis during first 18 months of life. BMJ 328(7450): 1223.

[20]. Benn CS, Wohlfahrt J, Aaby P, Westergaard T, Benfeldt E, et al. (2004) Breastfeeding and risk of atopic dermatitis, by parental history of allergy, during the first 18 months of life. Am J Epidemiol 160(3): 217-223.

[21]. Nohr EA, Frydenberg M, Henriksen TB, Olsen J (2006) Does low participation in cohort studies induce bias? Epidemiology 17(4): 413-418.

[22]. Olsen J, Melbye M, Olsen SF, Sørensen TI, Aaby P, et al. (2001) The Danish National Birth Cohort--its background, structure and aim. Scand J Public Health 29(4): 300-307.

[23]. Benn CS, Benfeldt E, Andersen PK, Olesen AB, Melbye M, et al. (2003) Atopic dermatitis in young children: diagnostic criteria for use in epidemiological studies based on telephone interviews. Acta Derm Venereol 83(5): 347-350.

[24]. Henderson J, Sherriff A, Farrow A, Ayres JG (2008) Household chemicals, persistent wheezing and lung function: effect modification by atopy? Eur Respir J 31(3): 547-554.

[25]. Peters JL, Suglia SF, Platts-Mills TA, Hosen J, Gold DR, et al. (2009) Relationships among prenatal aeroallergen exposure and maternal and cord blood IgE: project ACCESS. J Allergy Clin Immunol 123(5): 1041-1046.

[26]. Miller RL, Chew GL, Bell CA, Biedermann SA, Aggarwal M, et al. (2001) Prenatal exposure, maternal sensitization, and sensitization in utero to indoor allergens in an inner-city cohort. Am J Respir Crit Care Med 164(6): 995-1001.

[27]. Lim RH, Arredouani MS, Fedulov A, Kobzik L, Hubeau C (2007) Maternal allergic contact dermatitis causes increased asthma risk in offspring. Respir Res 8: 56.

[28]. Fedulov AV, Leme A, Yang Z, Dahl M, Lim R, et al. (2008) Pulmonary exposure to particles during pregnancy causes increased neonatal asthma susceptibility. Am J Respir Cell Mol Biol 38(1): 57-67.

[29]. Hamada K, Suzaki Y, Leme A, Ito T, Miyamoto K, et al. (2007) Exposure of pregnant mice to an air pollutant aerosol increases asthma susceptibility in offspring. J Toxicol Environ Health A 70(8): 688-695.

[30]. Bonnelykke K, Pipper CB, Bisgaard H (2008) Sensitization does not develop in utero. J Allergy Clin Immunol 121(3): 646-651. 